\title{
Spatial reference in weightlessness: Perceptual factors and mental representations
}

\author{
A. D. FRIEDERICI and W. J. M. LEVELT \\ Max-Planck-Institut für Psycholinguistik, Nijmegen, The Netherlands
}

\begin{abstract}
The role of gravity in spatial coordinate assignment and the mental representation of space were studied in three experiments, varying different perceptual cues systematically: the retinal, the visual background, the vestibular, and proprioceptive information. Verbal descriptions of visually presented arrays were required under different head positions (straight/tilt) and under different gravitational conditions (gravity present/gravity absent). The results of two experiments conducted with 2 subjects who participated in a space flight revealed that subjects are able to adequately assign positions in space in the absence of gravitational information, and that they do this by using their head-retinal coordinates as primary references. This indicates that they cognitively adapted to the perceptually new situation. The findings from a third experiment conducted with a larger group of subjects under a condition in which the gravitational information was present but irrelevant to the task being solved (subjects were in a horizontal supine position) show that subjects, in general, are flexible in using cues other than gravitational ones as references when the latter cannot serve as a referential system. These findings, together with the observation that consistent spatial assignment is possible even immediately after first exposure to the perceptually totally novel situation of weightlessness, seem to suggest that the mental representation of space, onto which given perceptual information is mapped, is independent of a particular percept.
\end{abstract}

Perception of, orientation in, and communication about space are some of the most fundamental abilities in human beings. These abilities, which involve the storage and retrieval of spatial information in and from memory, necessarily require the existence of some mental representation or model of space. On the basis of such a mental model, one's perception of, behavior in, and, moreover, communication about space are organized. Unambiguous localization in space necessarily requires a frame of reference with respect to which spatial positions are defined. Concepts such as "above" and "below," for example, can only be used with respect to a defined reference frame. The gravitational field of the physical world provides a basis for such a fixed reference frame, with respect to which the unambiguous assignment of spatial coordinates is, in principle, possible. The perceived gravitational ver-

The research reported here was supported by the German Max-PlanckGesellschaft and the Bundesministerium für Forschung und Technologie. A preliminary report on part of the data of Experiments 1 and 2 was given in Friederici and Levelt $(1986,1987)$. The present paper was written while the first author was holding a Heisenberg Fellowship awarded by the Deutsche Forschungsgemeinschaft. We thank Ger Desserjer, as well as Hans Fransen for his help in running Experiment 3 and analyzing the data. We are grateful to the science astronauts Reinhard Furrer and Wubbo Ockels, not only for serving as subjects, but also for their ingenuity at solving technical problems they encountered as experimenters in space. We also wish to thank Dave Irwin and two anonymous reviewers for their helpful comments on the manuscript. Correspondence may be addressed to A. D. Friederici, Institut für Psychologie, Freje Universität Berlin, Habelschwerdter Allee 45, 1000 Berlin 33, FRG. tical, although it may deviate from the objective vertical by some degrees (e.g., Aubert, 1861; Mittelsteadt, 1983), is normally used as a reference when the vertical has to be defined. Therefore, it has been argued that the earth's gravitational field is the dominant constraint for reference choice, at least when space is perceived (Rock, 1973; Shepard \& Hurwitz, 1984).

A most intriguing question is whether this salient perceptual property of space constrains not only the perception but also the conceptualization or mental representation of space. At least when one images objects and scenes, properties of the real world are mentally reflected insofar as these mental images seem to appear in their normal upright orientation. Although the available theories of mental imagery do not deal with this issue explicitly (e.g., Kosslyn \& Shwartz, 1978; Pinker, 1980; Pinker \& Kosslyn, 1978; Pylyshyn, 1973, 1980), it does seem that in order for one to achieve such mental images, the aspect of verticality must be encoded in the mental representations that underlie this cognitive process. If verticality encoded in spatial concepts is directly linked to the dominant perceptual information of gravity, we would predict spatial assignments to be quite indeterminate when this information is not available. If, however, mental representations encode verticality more or less independently from perceived gravity, unambiguous assignment of a spatial orientation should be possible even in the absence of gravitational information. In such a situation, the interpretation of ambiguous visual information would have to be based on some other frame of reference provided 
by oriented visual background, the body's axis, or the head-retinal coordinates themselves.

The actual reference used for spatial assignment in the absence of gravity is an empirical issue that has not been investigated so far. Since experimentation on earth allows one to test only the relative role of gravity versus other perceptual cues for spatial coordinate assignment, we used weightlessness as the critical condition to determine the absolute role of gravity in the assignment of spatial relations. In the present paper, we report the spatial assignment of 2 subjects under the very special perceptual condition of weightlessness, as well as results from a test with a larger group of subjects under a perceptual condition in which gravity was present but irrelevant for the task being solved (the subjects were in a horizontal supine position). In particular, we studied subjects' abilities to name spatial relations, for we consider observable language behavior to be one of the primary means of making the use of spatial concepts explicit. Note that such a task involves more than a simple perceptual process. Verbal descriptions of this kind require a perceptual stage, a stage in which perceptual cues are mapped onto a spatial concept, and the verbalization of this concept.

Before turning to the experiments themselves, we will briefly review how different types of perceptual information determine spatial perception under normal conditions of gravity, since the perceptual processes necessarily precede the verbal spatial assignment tested on tasks in our experiments.

When trying to specify the perceptual constraints on frame of reference, one must consider at least three types of perceptual cues: visual, vestibular, and proprioceptive input information. It is generally assumed that possible conflicts between different types of information are solved by weighting the cues differently, whether at lower or at higher levels of processing (e.g., von Holst, 1950; Kohler, 1955; Levelt, 1984). These weighting procedures have been examined in various studies. When gravitational vertical and the vertical indicated by the visual background are brought into conflict, the perception of a vertical line can be influenced by off-vertical visual frames (Ebenholtz, 1977; Witkin \& Asch, 1948) and by off-vertical visual background information (Bischof \& Scheerer, 1970; Müller, 1916), as well as by rotating visual displays (Dichgans, Held, Young, \& Brandt, 1972; Mauritz, Dichgans, \& Hufschmidt, 1977).

The experiments in which the conflict between gravitational and retinal information has been studied by means of the observer's head tilt are not univocal. Whether the reference frame chosen is primarily head-retinal or gravitational seems to depend on the task and the type of perceived visual information (e.g., Corballis, Anuza, \& Blake, 1978; Corballis, Nagoury, Shetzer, \& Stefanatos, 1978; Rock, 1956). Attneave and Olson (1967) showed that subjects are in principle able to use either gravitational or retinal coordinates as references, in accordance with a task's instructions. Reactions, however, were faster with respect to environmental as opposed to retinal coordinates, suggesting that-at least in normal adults-the gravitational orientation is dominant.

Studies in which spatial assignment has been examined with subjects in different body positions suggest that subjects use the gravitationally defined vertical as a reference when standing upright, but the body-defined vertical when in a supine position (Rock, 1956). Again, subjects in a supine position are able to indicate gravitational coordinates, when they are required to do so. Subjects do this, however, with a constant subjective deviance from the gravitational vertical. It has been proposed that this deviance results from an interaction of the gravity vector and a person's idiotropic vector (Mittelsteadt, 1983).

When the gravitational, the body-defined, and the retinally defined verticals were brought into conflict by varying the head and body positions during a luminous line setting task, deviations from the objective body-defined vertical were smaller in the vertical body position than in the supine body position when the head was straight (Parker, Poston, \& Gulledge, 1983; Templeton, 1973), but they were equally large when the head was tilted (Parker et al., 1983). From the combined studies, it seems that, although in principle other reference systems can be used, gravitational information is dominant when it comes to orientation in space or to the assignment of verticality to visually perceived information.

The central question in the present study was whether or not different perceptual factors would affect the use of spatial concepts, and if so, how. We report here three experiments: In two of them, we tested subjects' spatial assignment before, during, and after exposure to weightlessness; in the third experiment, we tested a group of subjects in a situation in which gravitational information was present but not relevant for the task being solved. During the third experiment, the subjects were in a supine body position, and spatial assignment was required in a plane orthogonal to perceived gravity. Due to the exceptional experimental condition of microgravity, which for any period longer than $30 \mathrm{sec}$ can only be achieved during a space flight, we had to meet certain constraints concerning the number of subjects ( 2 astronauts), as well as the number and the length of test sessions (see below). The first of the two experiments in space was designed to test whether subjects would, in principle, be able to solve the task of spatial assignment in weightlessness. The second experiment was designed to evaluate which coordinates are used as references for the assignment of spatial positions in the absence of gravity. An earlier study involving a luminous line setting task during weightlessness had suggested that subjects in the presence of minimal tactile cues show a high degree of accuracy on such a task (Graybiel et al., 1967). In the present experiment, however, no tactile cues were available during the tests in weightlessness, since the subjects were free floating. In 
the third experiment, gravitational force was present, but it could not serve as reference, because visual stimuli were presented in a plane orthogonal to the perceived gravity.

\section{EXPERIMENT 1}

\section{Method}

\section{Subjects}

The subjects were 2 male payload specialists (PS2 and PS3) who were part of the crew of the D1 Spacelab Mission in 1985.

\section{Stimuli and Apparatus}

The stimuli were visual arrays in which Factors A and B were varied. As Factor A, a white ball and a black ball of the same size were displayed under different orientations at the center of the visual field. As Factor B, two intrinsically oriented objects (two line drawings of trees) were displayed to the left and to the right of the balls (see Figure 1 for examples of the stimulus items with trees and balls included). Note that the actual stimuli presented in the experiment were negatives of these examples-that is, white line drawings of balls and trees on a black background.

The orientation of the (virtual) connecting axis of the two balls varied in steps of $7^{\circ}$ clockwise and counterclockwise from the vertical $\left(180^{\circ}\right.$ and $\left.360^{\circ}\right)$, and horizontal $\left(90^{\circ}\right.$ and $\left.270^{\circ}\right)$. Including the vertical and horizontal positions, the objects were displayed in 12 different axes of orientation. The visual background information was provided by two intrinsically oriented objects (the trees) that were oriented toward the vertical (with their tops at $180^{\circ}$ and $360^{\circ}$ ), the horizontal (with their tops at $90^{\circ}$ and $270^{\circ}$ ), and in $7^{\circ}$ steps and $14^{\circ}$ steps clockwise and counterclockwise off vertical and off horizontal. Each of the three ball positions within one of the two horizontal domains $\left(180^{\circ}\right.$ and $\left.360^{\circ}\right)$ or the two vertical domains $\left(90^{\circ}\right.$ and $\left.270^{\circ}\right)$ was crossed with each of the five tree orientations within that same domain, resulting in 60 stimulus items $(3 \times 5 \times 4)$. Figure 2 gives a schematic representation of the systematics underlying the construction of the stimulus material.

In addition to these 60 stimuli, the intrinsically nonoriented objects (the balls) were displayed in all ball positions without the visual background information of the intrinsically oriented trees, resulting in a total of 72 stimuli. For a practical reason (the length of commercial film), the item set was partitioned into two subsets of 36 items each, with each subset in random order. The stimuli (see Figure 1) were presented as negatives-white line drawings on a black background-in a specially designed apparatus (VISOS), a kind of viewing device that prevented the subjects from using any visual cue other than the one that was experimentally varied. Due to the black background, possible additional cues from the rectangular picture frame were eliminated. The hardware consisted of a viewing aid mounted on a commercial camera: Olympus camera OM-2 plus Olympus Winder 2 with remote control, a Pentax Stereo Viewer II, a microcassette recorder (Pearlcorder S801), and a pair of goggles (Schweisser-Schutzbrille, Firma Auer, Berlin). A window was cut in the back of the camera and the stereo viewer was placed over this window. The eyepieces of the stereo viewer were built into the goggles. For reasons of safety, the glass front of the goggles was replaced with a piece of metal. In order to allow incidence of light without any other visual information, a frosted "glass" (polycarbonate) was put over the lens of the camera. The winder, operated by remote control, transported developed (Agfa F0 71P) films containing the stimulus material. Two films with 36 stimuli each were used. The microcassette recorder was attached to the bottom of the winder. The winder as well as the recorder were batteryoperated. The VISOS was equipped with an adjustable headband that permitted the attachment of the apparatus to each subject's head.

\section{Procedure}

The subjects were required to describe the position of the white ball with respect to the black ball by using words such as "above," "below," "left," and "right," as well as combinations of them. Each subject performed the task in his native language, PS2 in German and PS3 in Dutch. Note that in Dutch as well as in German, constructions such as "above and to the right" consist of only two words-"rechts oben" and "rechts boven," respectively. The subjects were asked to respond as accurately and as quickly as possible. No further instructions were given, in order to allow an unbiased and spontaneous choice of reference. This procedure seemed the most revealing, given the fact that similar experiments had thus far not been carried out during a space flight, and given the time constraints on the crew before, during, and after the mission, which did not allow for multiple testing (e.g., for performing the task under different instructions). The subjects controlled the exposure du-

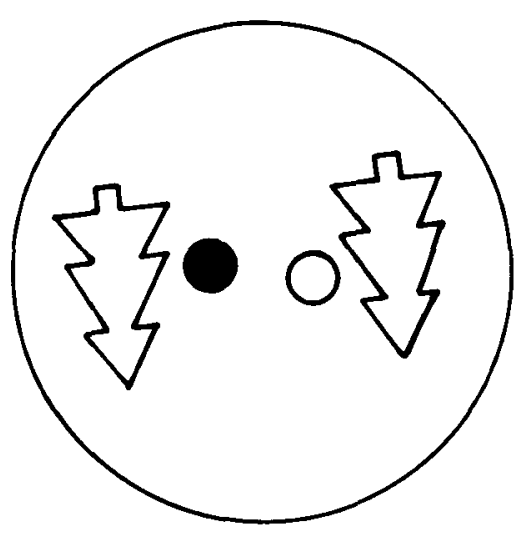

A

Ball Position: $97^{\circ}$

Tree Orientation: $173^{\circ}$

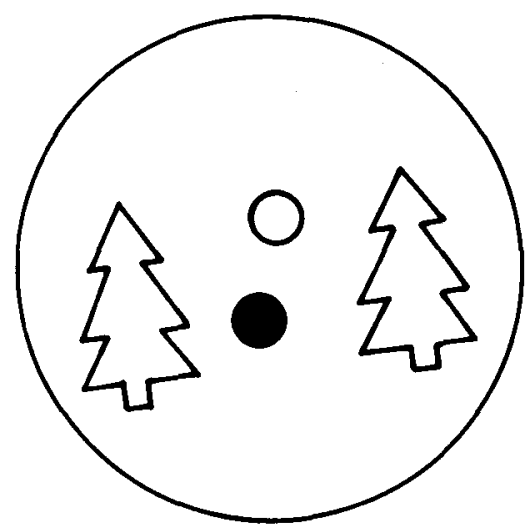

B

Ball Position: $7^{\circ}$

Tree Orientation: $353^{\circ}$

Figure 1. Examples of test items. 


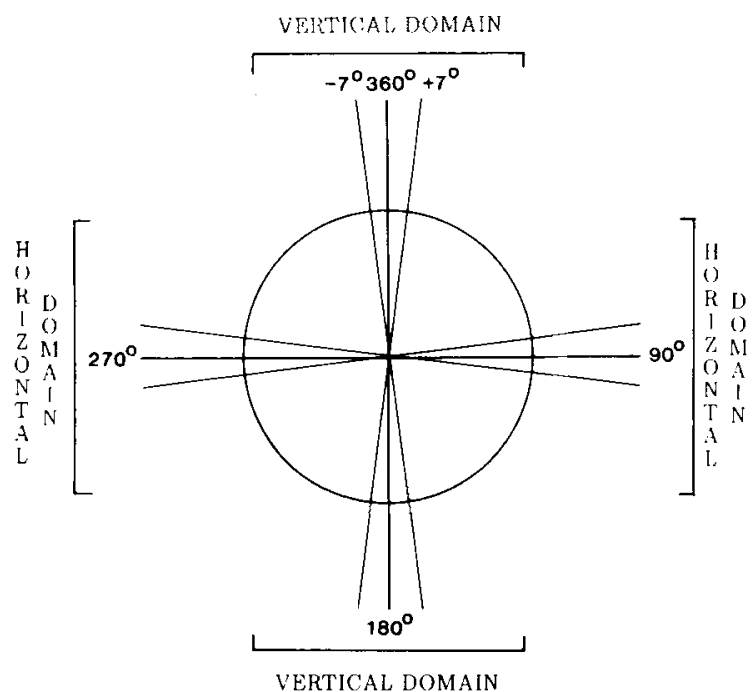

BALL POSITION

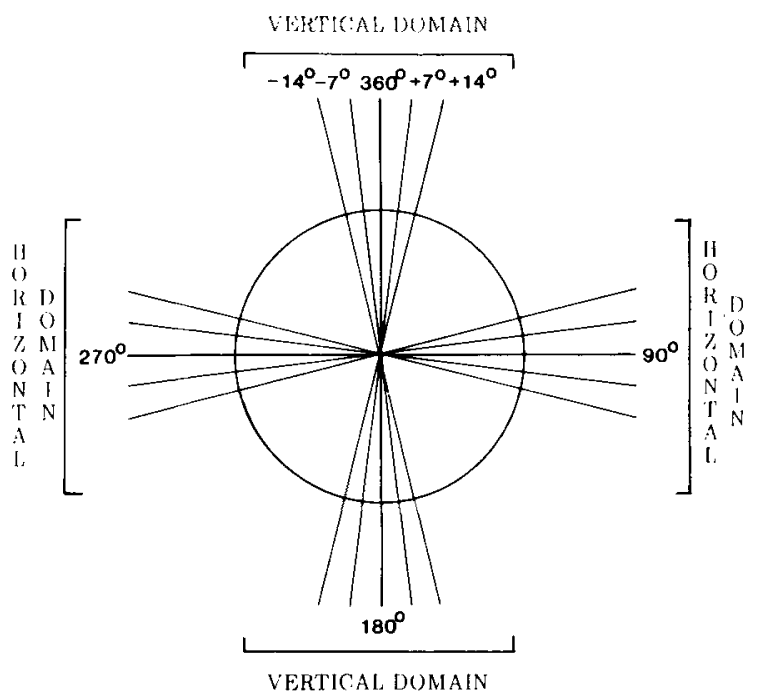

TREE ORIENTATION

Figure 2. Illustration of all ball positions and tree orientations used in the test material. Ball position is defined as the position of the white ball to be described with respect to that of the black ball. Ball positions and tree orientations were completely crossed.

ration of each trial as well as the presentation of the next trial by pressing the remote control button. The subjects' verbal responses ware tape-recorded for later analysis. There were three experimental conditions varying Factor $\mathrm{C}$, gravity condition: preflight, inflight, and postflight tests. During preflight and postflight sessions, the subjects were standing upright with their heads upright. During these sessions, each subject's head position was controlled by a fixed position of the goggles, which were mounted on a tripod. Under $1 \mathrm{~g}$, a tripod was used, because the camera was too heavy to be held by a headband only. The subject stood in front of the tripod, looking into the goggles, and the headband was used to make sure that the goggles fit the subject's head tightly, so that no additional light cues (from the dimmed room) would be available. During the two inflight sessions, the subjects were free floating. Each subject was required to keep his head straight, aligned with the axis of the body. The subject's head position was monitored throughout the inflight test by the space experimenter (another astronaut). The preflight test was carried out 85 days before the flight ( $L-85$ days). A first inflight session was performed $2 \mathrm{~h}$ after launch $(\mathrm{L}+2 \mathrm{~h})$ on the middeck of the space shuttle. A second test session was performed on the Ist day after launch $(\mathrm{L}+1$ day) in the spacelab. Postflight tests were conducted after the subjects had been exposed 7 days to weightlessness, on the 1 st day after their return to earth $(R+1$ day) and again about 3 months after the space flight $(R+104$ days and $R+108$ days, respectively). Immediate postflight tests $(R+18 \mathrm{~h}$ and $R+19 h$ ) were conducted in the airplane taking the subjects from Edwards Air Force Base, in California, to the NASA Kennedy Space Center in Florida, where baseline data collection took place. Unfortunately, due to the background noise in the jet, the quality of the recording was reduced, so that measurements of the response latencies from these tapes were impossible. Thus, for these test sessions, only qualitative data are available.

\section{Results}

Verbal responses were analyzed with respect to the type of reference frame chosen and their correctness for a given type of frame, as well as with respect to latency. To determine the computational load of each response, both cor- rectness and latency measures were taken. Responses were classified into three types: (1) those correct with respect to the visual background information; (2) those correct with respect to the coordinates jointly indicated by the body-defined and the head-retinal axis during weightlessness, and by these along with the gravitational vertical, when it was present; and (3) those incompatible with any reference frame. Note that, in some instances, responses could be correct with respect to one reference frame or more. Take, for example, Example A in Figure 1. In the case of the visual background reference, the response for this item would be: "The white ball is above and to the left of the black ball." Because this response is not compatible with any other reference (e.g., the head-retinal/ body-defined vertical), such an answer would be scored as exclusively correct with respect to the visual background. Example B shows a case in which an answer correct with respect to the visual background ("The white ball is above and to the right of the black ball') is also correct with respect to the head-retinal/body-defined vertical. Such an answer would be scored as inclusively correct with respect to the visual background. The principle of this overlap between different reference frames and the actual number of items in each category is given in Figure 3. The percentages of the different response types (correct with respect to visual background and head-reti$\mathrm{nal} /$ body-defined reference) presented in Table 1 represent $X$-inclusive scores. Because the general pattern of $X$ inclusive and $X$-exclusive scores are alike, only $X$ inclusive scores are presented.

In addition to this qualitative rating, response latencies were taken. Time was measured from the picture onset to the onset of the speaker's verbal response. These latencies were analyzed not with an automatic voicekey, which 

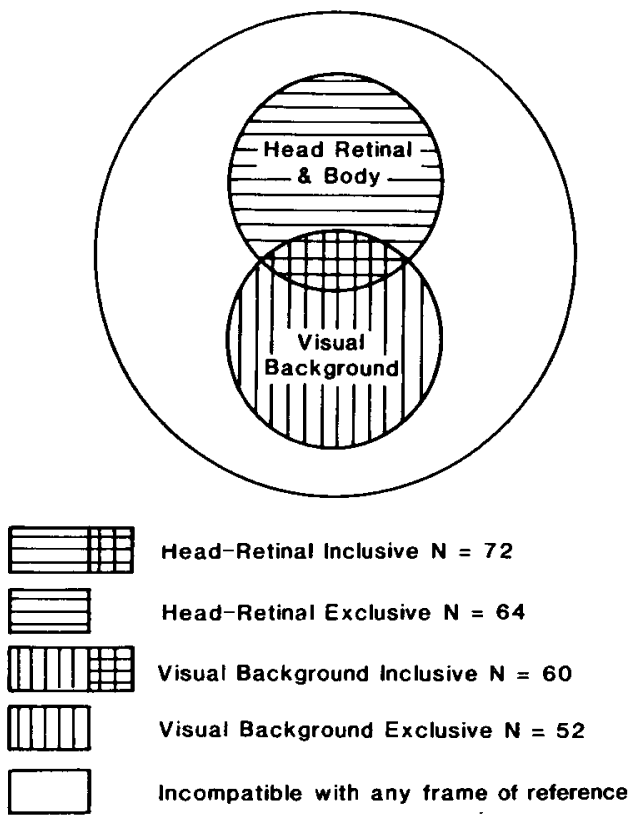

Figure 3. Schematic graph of the overlap of reference frames in Experiment 1.

could have been triggered by uncontrollable background noise from the spacelab, but with a technique that allowed most accurate measures. An oscillograph displayed the acoustic signal of each trial visually. Latencies were measured from the picture onset, which was marked by the noise resulting from the opening of the shutter of the camera, to the onset of the speaker's voice. Each latency was thus measured individually. Below, we will present a qualitative analysis of the reference choice, followed by an analysis of the latencies for the verbal responses.

\section{Reference Choice}

The analysis of type of reference chosen under the different conditions clearly indicates that the 2 subjects rarely use the intrinsically oriented objects of the visual background as a reference frame, whether in preflight tests, in postflight tests, or in weightlessness. Table 1 displays the percentages of all responses that were correct with respect to a given reference frame ( $X$-inclusive scores). Note here that because there were responses correct with respect to more than one reference frame, the percentages given in Table 1 may add up to more than $100 \%$.

Preflight. Both subjects used a reference frame that was dictated by the coinciding gravitational, body-defined, and head-retinal verticals. Their correct descriptions with respect to this reference frame were very high. The visual background was hardly ever used exclusively as the reference frame (PS2, 1.7\%; PS3, 0\%).

Inflight. Both subjects predominantly used the coinciding head-retinal and body-defined verticals as references. Again, visual background cues were rarely, if ever, used as reference frames, as indicated by the low percent- ages of responses that were correct exclusively with respect to this reference (Inflight 1-PS2, 3.3\%; PS3, 0\%. Inflight 2-PS2, 8.3\%; PS3, 1.7\%). When comparing preflight and the first inflight test with respect to the number of responses that were incompatible with any reference frame, we see that PS2, in contrast to PS3, demonstrates a slight increase of descriptions of this type. A McNemar test for change indicates that this increase is significant $\left(\chi^{2}=5.82, p<.05\right)$. As we will see below, this increase in responses incompatible with respect to any reference frame was not independent of the subjects' reaction times.

Postflight. Immediately postflight, both subjects used the coordinates jointly indicated by the gravitational, bodydefined, and head-retinal verticals. The level of accuracy remained the same, as compared with the inflight performance for both subjects. In the first postflight tests, Subject PS3 showed a performance similar to that on the preflight baseline test, whereas Subject PS2 showed a number of responses not compatible with any reference frame, which was similar to his performance on the inflight tests. But note that, in general, the number of responses in this category was very low (see Table 1).

\section{Response Latency}

The data presented are the latencies measured from the onset of the visual display to the onset of the verbal output. Extreme values, defined as response latencies that were off the subject's mean by two standard deviations, and missing data points were replaced by the subject's mean per condition. For PS2, a total of $14.6 \%$ data points, and for PS3, a total of $7.6 \%$ data points were replaced. Response latencies for the different conditions per subject are displayed in Table 2.

Because no reaction time measures could be taken from the first postflight session, the analysis was computed over the four remaining test sessions. Separate analysis of variance were carried out for the 2 subjects over items, with sessions as the repeated measure. We are aware of the problems involved in using an ANOVA in single case studies, so we set the level of significance at a conservative $1 \%$. We will, however, also give the results that reached the $5 \%$ level of significance. In addition, we will report omega square values as a measure of percent of variance accounted for by a particular factor.

A four-way analysis of variance was conducted with the following factors: (1) ball position (rectilinear, oblique $-7^{\circ}$, oblique $+7^{\circ}$ ); (2) tree orientation (rectilinear, oblique $-14^{\circ}$, oblique $-7^{\circ}$, oblique $+7^{\circ}$, oblique $+14^{\circ}$, no tree); (3) domain (vertical, horizontal), whereby the vertical domain covered all items with ball position and tree orientation at and around $360^{\circ}$ and $180^{\circ}$ and the horizontal domain covered positions at and around $90^{\circ}$ and $270^{\circ}$; (4) gravity $(1 \mathrm{~g}$, preflight; $0 \mathrm{~g}$, inflight $\mathrm{L}+2 \mathrm{~h}$; $0 \mathrm{~g}$, inflight $\mathrm{L}+1$ day; $1 \mathrm{~g}$, postflight).

Separate analysis for the 2 subjects revealed a main effect of gravity for both PS2 $[F(3,3)=9.43, p<.05$, accounting for $17.38 \%$ of the variance] and PS3 
Table 1

Experiment 1: Percentage of Responses with Respect to Different Reference Frames per Subject and Flight Condition

\begin{tabular}{|c|c|c|c|c|c|}
\hline \multirow{3}{*}{$\begin{array}{c}\text { Reference } \\
\text { Frame }\end{array}$} & \multirow{3}{*}{$\begin{array}{c}\text { Preflight } \\
\text { L-85 days }\end{array}$} & \multirow{2}{*}{\multicolumn{2}{|c|}{ Inflight }} & \multicolumn{2}{|c|}{ Postflight } \\
\hline & & & & \multirow{2}{*}{$\begin{array}{l}R+18 h / \\
R+19 h\end{array}$} & \multirow{2}{*}{$\begin{array}{l}R+108 \text { days } \\
R+104 \text { days }\end{array}$} \\
\hline & & $L+2 h$ & $L+1$ day & & \\
\hline \multicolumn{6}{|c|}{ Subject PS2 } \\
\hline Head-retinal & 97.2 & 87.5 & 83.3 & 79.2 & 77.8 \\
\hline Visual background & 11.7 & 16.7 & 21.7 & 21.7 & 16.7 \\
\hline None & 1.4 & 13.9 & 9.7 & 13.9 & 19.4 \\
\hline \multicolumn{6}{|c|}{ Subject PS3 } \\
\hline Head-retinal & 93.1 & 97.2 & 95.8 & 90.3 & 87.5 \\
\hline Visual background & 13.3 & 13.3 & 15.0 & 13.3 & 13.3 \\
\hline None & 6.9 & 2.8 & 2.8 & 9.7 & 12.9 \\
\hline
\end{tabular}

Note-Responses are displayed as percentage of all responses correct with respect to a given reference frame ( $X$-inclusive scores; see Figure 3 ). The head-retinal coordinates coincide with the body coordinates, and also with the gravitational coordinates during pre- and postflight tests. $\mathrm{L}=$ launch, $\mathrm{R}=$ return.

$[F(3,3)=25.83, p<.01$, accounting for $28.03 \%$ of the variance]. Note that PS2 also demonstrated an increase in the number of descriptions that were incompatible with any reference frame. Post hoc Newman-Keuls tests revealed that PS3 showed significantly longer response latencies for the first inflight as compared with the preflight test (critical difference at the $1 \%$ level of significance: $W 4=158.46$ ). No other main effect or interaction was significant for PS3. PS2 only showed a significant four-way interaction $[F(30,30)=2.45, p<.05$, accounting for $2.37 \%$ of the variance].

\section{Discussion}

The results from the 2 subjects show that consistent assignment of spatial reference is possible under the absence of gravitational information, suggesting that verticality can be assigned independently of perceived gravity. Second, it is clear that visual background information, as provided by the trees' orientation, is not used as the primary reference frame for spatial terms, whether in $1 \mathrm{~g}$ or in $0 \mathrm{~g}$. Although the visual background given in this study may be considered quite abstract, this visual background can definitely serve as a reference frame when subjects are instructed to use it thus (Friederici, 1989b). Moreover, we know from perception studies that even such abstract visual backgrounds as single lines or a simple rectangular frame are effective visual backgrounds (e.g., Ebenholtz, 1977; Müller, 1916; Witkin \& Asch, 1948). Thus, the result that 2 subjects did not use the visual background as a reference frame cannot be attributed to its "nonnaturalness" or "schematicness."

The finding that subjects are quite able to assign space in the absence of gravity agrees with an earlier space experiment, in which subjects in weightlessness were able to set a luminous line with great accuracy in the absence of gravity - at least when tactile cues were present (Graybiel et al., 1967). The present data indicate that accurate spatial assignment and the use of spatial concepts are possible in weightlessness, even when tactile cues are absent (i.e., when subjects are free floating). The finding that subjects on earth use the coordinate system indicated by the gravitational, the body-defined, and the head-retinal verticals, rather than the visual background, as a reference frame in $1 \mathrm{~g}$ when standing upright agrees with results from a related experiment with a group of students under the same condition (Friederici, 1989a). It is furthermore congruent with results from experiments on the identification of alphanumeric characters under a tilted rectangular frame under normal gravitational conditions (Corballis, Nagoury, et al., 1978). The data from the condition of weightlessness indicate that visual background information is not used as a primary reference for spatial assignment even when gravitational cues are not available. In weightlessness, both subjects used the coordinate system indicated by the body-defined and the head-retinal verticals as the primary reference.

The evaluation of both the qualitative and the quantitative data reveals that the computational load for both subjects is larger in the perceptually novel situation of weight-

Table 2

Experiment 1: Mean Reaction Times in Milliseconds per Subject and Flight Condition

\begin{tabular}{|c|c|c|c|c|c|c|c|c|}
\hline \multirow[b]{3}{*}{ Subject } & \multirow{2}{*}{\multicolumn{2}{|c|}{ Preflight L-85 }} & \multicolumn{4}{|c|}{ Inflight } & \multirow{2}{*}{\multicolumn{2}{|c|}{$\begin{array}{c}\text { Postflight } \\
R+108 \text { days } / R+104 \text { days }\end{array}$}} \\
\hline & & & \multicolumn{2}{|c|}{$L+2 h$} & \multicolumn{2}{|c|}{$L+1$ day } & & \\
\hline & $M$ & $S D$ & $M$ & $S D$ & $M$ & $S D$ & $M$ & $S D$ \\
\hline PS2 & 1130 & 198 & 1102 & 345 & 1046 & 133 & 858 & 163 \\
\hline PS3 & 737 & 156 & 1003 & 199 & 781 & 146 & 883 & 141 \\
\hline
\end{tabular}

Note- $\mathrm{L}=$ launch, $\mathbf{R}=$ return. 
lessness, as is indicated by an increase in inadequate descriptions for PS2 and an increase in response time for PS3. The finding that both subjects were, however, in principle able to use spatial concepts consistently and correctly with respect to a particular reference frame immediately after first exposure to weightlessness indicates that the mental representations involved in this task are abstract enough to allow mappings from the perceptually totally novel situations.

Some hours after return to earth, both subjects' response latencies were not prolonged, as compared with latencies in preflight tests. Accuracy of responses, however, decreased slightly for both subjects. If we consider both accuracy and speed of response as indicators of processing load, this result seems partly to agree with an earlier study on spatial perception, in which, on their return to earth after a 7-day exposure to weightlessness, subjects were tested with a rod-and-frame test. It was found that the time to make judgments of the vertical was increased postflight, as compared with preflight, for the 4 subjects tested, whereas accuracy of responses decreased in 2 out of 4 subjects (Young, Oman, Kenyon, \& Arrott, 1986; Young, Oman, Watt, Money, \& Lichtenberg, 1984). Despite a slight increase in responses incompatible with respect to any reference, the 2 subjects tested here showed surprisingly few problems in readapting to the earth's environmental situation. They described most of the spatial arrays accurately with respect to the gravitational frame even shortly after return to earth, and they were able to do so without using additional computational time.

The prominent result from Experiment 1 is that subjects are able to use spatial concepts immediately after first exposure to the perceptually novel situation of weightlessness, suggesting that the perceptually novel information about space is mapped onto a representation that encodes verticality independent of the particular frame of reference provided by the apparent gravity. The task of spatial assignment is solved by choosing some frame of reference other than the gravitational for the assignment of verticality. Experiment 2 was designed to determine which of the possible reference frames was actually used to accomplish the task of spatial assignment in weightlessness.

\section{EXPERIMENT 2}

Experiment 2 was conducted in order to examine whether the body-defined or the head-retinal coordinates are used to assign spatial orientation in weightlessness. The critical variable in Experiment 2 was the position of the subject's head. By controlling for the tilt of the head, we sought to disentangle the body-defined and the head-retinal defined coordinate systems. Although the head and the retinal axes may be distinct due to a possible ocular counterrolling during head tilt, our discussion of Experiment 2 will not distinguish between these two axes, since the minimal stimulus variation in the present experiment was $7^{\circ}$, whereas the subjects' individual means of ocular counterrolling were $4^{\circ}$ and $5^{\circ}$, respectively, under normal gravitational conditions and were most possibly reduced under microgravity (Baumgarten et al., 1987).

\section{Method}

\section{Subjects}

The subjects participating in Experiment 2 were the same as those in Experiment 1.

\section{Stimuli and Apparatus}

The apparatus used in this experiment was the same as in Experiment 1 , as was the stimulus material.

\section{Procedure}

In Experiment 2, the subjects were required to verbally describe visually presented arrays when their heads were tilted. Both subjects responded to all 72 stimulus items with their heads tilted approximately $30^{\circ}-35^{\circ}$. Half the stimulus items were presented when the subject's head was tilted to the left and half when the head was tilted to the right. These tests under the head-tilt condition were performed in microgravity (inflight $\mathrm{L}+1$ day) as well as in $1 \mathrm{~g}$ (postflight tests). During inflight sessions, the subjects were free floating and head tilt was controlled for by the experimenter, who monitored each subject throughout the task. In order to avoid tactile cues, we decided not to use an additional apparatus to fix the subject's head. The subject was continuously monitored for head position during the test session by the space experimenter (one of the astronauts). During postflight sessions, the subjects were standing upright with their heads tilted to the left or right. During these test sessions, each subject's head tilt was controlled by a fixed tilt position of the goggles, which were mounted on a tripod. Under $1 \mathrm{~g}$, a tripod was used, because the camera was too heavy to be held by a headband only. During these sessions, the subjects stood in front of the tripod, looking into the goggles, and the headband was used to make sure that the goggles fit tightly against each subject's head, so that no additional light cues (from the dimmed room) would be available.

\section{Results}

As in Experiment 1, verbal responses were analyzed with respect to reference choice and response latencies. Responses were classified into four types: (1) responses that were correct with respect to the visual background; (2) responses that were correct with respect to the head-retinal coordinates; (3) responses that were correct with respect to the body-defined coordinates, which were identical with the gravitational coordinates if the latter were present; and (4) responses that were incompatible with respect to any given reference frame. Note that, in some instances, responses could be correct with respect to two or even three reference frames. Figure 4 schematically displays the distribution of the possible overlaps of the different reference frames. The percentages displayed in Table 3 are $X$-inclusive scores. Figure 5 gives an example of an item in which the head-retinal, the bodydefined, and the gravitationally defined coordinates overlap under head tilt for the displayed target.

\section{Reference Choice}

The results of this experiment under head tilt clearly demonstrate what type of reference is used under the 

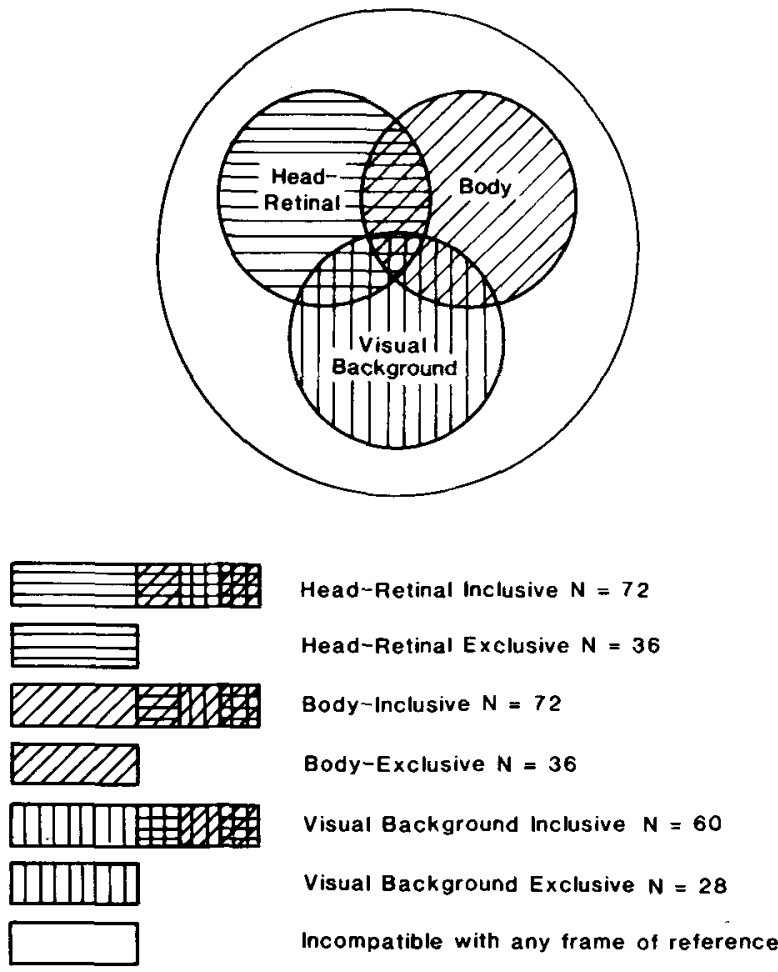

Figure 4. Schematic graph of the overlap of reference frames in Experiment 2.

different gravitational conditions. Table 3 gives the percentages of responses correct with respect to the intrinsically oriented visual background, the head-retinal vertical, or the body-defined vertical, which under $1 \mathrm{~g}$ coincides with the gravitational vertical ( $X$-inclusive scores), and of those incompatible with respect to any reference (none). Because the responses were sometimes correct with respect to more than one reference frame (see Figure 4), the percentages add up to more than $100 \%$.

From the data displayed in Table 3 , it is evident that reference frames used in weightlessness are distinct from those used when one is standing upright in $1 \mathrm{~g}$. In weightlessness, both subjects predominantly used the head-retinal coordinates as the reference frame and not the bodydefined coordinates (as under $1 \mathrm{~g}$ ) or those defined by the visual background. In $1 \mathrm{~g}$, both subjects used the coordinates indicated by the gravitational and body-defined vertical. Visual background information was almost never chosen exclusively as the primary reference, whether under $1 \mathrm{~g}$ (Postflight 1-PS2, 0\%; PS3, 0\%. Postflight 2PS2, $1.7 \%$; PS3, $0 \%$ ) or under $0 \mathrm{~g}$ (PS2, 1.7\%; PS3, $3.3 \%$ ). In particular, there is a clear difference in the distribution of reference frames between the test in weightlessness and the first postflight test (for an illustration of this change, see Figure 6).

Both subjects used the head-retinal reference more often than the body-defined reference frame in weightlessness, whereas in $1 \mathrm{~g}$, the gravitationally and body-defined refer- ence frame was used. A McNemar test for change over the head-retinal responses between the inflight and the immediate postflight test on the first day after return to earth reveals that this change is significant [PS2, $\chi^{2}=$ $14.8, p<.001 ;$ PS3, $\left.\chi^{2}=14.7, p<.001\right]$. There was no significant change between the immediate postflight test and the second postflight tests on $\mathrm{R}+104$ days for PS3 and R+108 days for PS2. The subjects' computational load for this task of spatial assignment under the different perceptual conditions was also analyzed by studying the response latencies.

\section{Response Latency}

Response latencies were analyzed as in Experiment 1. Extreme values and missing data points were replaced per subject by the conditions' means (PS2, 17.1\%; PS3, $6.3 \%$ ). Table 4 gives the mean response latencies and the standard deviations for each subject per condition. Note that the means for head tilt are based on 72 observations collapsing over head left and head right conditions. Because an analysis over each head tilt position did not reveal a significant main effect, the two head positions were pooled together. Two separate four-way analyses were calculated for each subject over items, with sessions as the repeated measure.

The factors involved were ball position $x$ tree orientation $\times$ domain $\times$ gravity. The analysis revealed no significant main effects for PS2. There was a ball $\times$ domain interaction at the $5 \%$ level of significance $[F(2,2)=$ $23.11, p<.05$, accounting for $2.23 \%$ of the variance]. Given the level of significance chosen $(1 \%)$ and the percentage of variance that this interaction accounts for, we are reluctant to interpret this interaction. For PS3, there were no significant main effects. Due to large standard deviations for the inflight test, the apparent difference between the different gravitational conditions is not significant. Thus, the gravity $\times$ domain interaction only reached

Table 3

Experiment 2: Percentage of Responses with Respect to Different Reference Frames per Subject and Flight Condition

\begin{tabular}{|c|c|c|c|}
\hline \multirow[b]{2}{*}{$\begin{array}{l}\text { Reference } \\
\text { Frame }\end{array}$} & \multirow[b]{2}{*}{$\begin{array}{c}\text { Inflight } \\
\text { L + } 1 \text { day }\end{array}$} & \multicolumn{2}{|c|}{ Postflight } \\
\hline & & $\mathbf{R}+1$ day & $\begin{array}{l}R+108 \text { days } \\
R+104 \text { days }\end{array}$ \\
\hline \multicolumn{4}{|c|}{ Subject PS2 } \\
\hline $\begin{array}{l}\text { Head-retinal } \\
\text { Body } \\
\text { Visual background } \\
\text { None }\end{array}$ & $\begin{array}{l}77.8 \\
44.4 \\
40.0 \\
11.1\end{array}$ & $\begin{array}{r}38.9 \\
98.6 \\
56.7 \\
1.4\end{array}$ & $\begin{array}{c}48.6 \\
76.4 \\
55.0 \\
0\end{array}$ \\
\hline \multicolumn{4}{|c|}{ Subject PS3 } \\
\hline $\begin{array}{l}\text { Head-retinal } \\
\text { Body } \\
\text { Visual background } \\
\text { None }\end{array}$ & $\begin{array}{r}76.4 \\
27.8 \\
55.0 \\
1.4\end{array}$ & $\begin{array}{r}47.2 \\
76.4 \\
46.7 \\
6.9\end{array}$ & $\begin{array}{r}41.7 \\
93.1 \\
38.3 \\
1.4\end{array}$ \\
\hline
\end{tabular}

Note-Responses are displayed as percentage of all responses correct with respect to a given reference frame ( $X$-inclusive scores; see Figure 4). The body coordinates coincide with the gravitational coordinates during postflight tests. $\mathrm{L}=$ launch, $\mathrm{R}=$ return. 

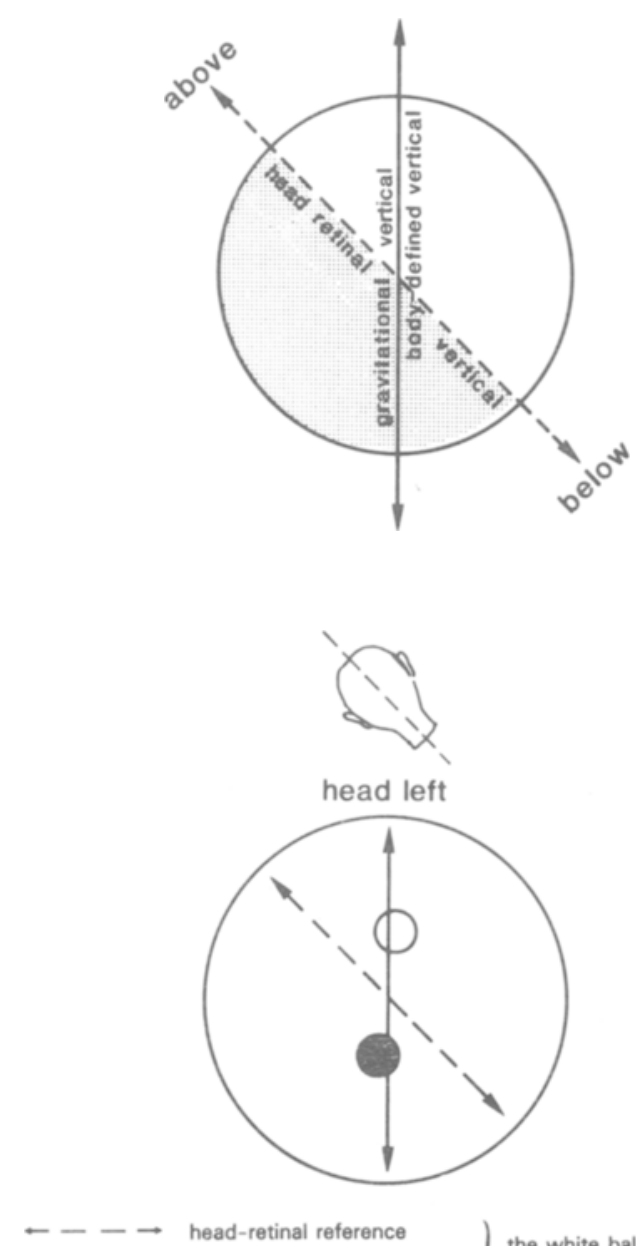

the white ball is above and to the right of the black bal

Figure 5. Illustration of a verbal description of the same visual array that is correct with respect to two reference frames (here: head-retinal and body/gravity-defined frame).

the $5 \%$ level of significance $[F(1,1)=193.51, p<.05$, accounting for less than $1 \%$ of the variance].

\section{Discussion}

The qualitative analysis shows that subjects use different reference systems in the presence and absence of gravitational information: In $1 \mathrm{~g}$, the coordinate system indicated by the gravitational and by the body-defined vertical is primary, whereas in microgravity, the head-retinal reference frame and not the body-defined frame is dominant, as indicated by responses under head tilt. The reaction time analysis in Experiment 2 reveals that, in contrast with the results of the head straight condition of Experiment 1, the subjects show no statistically reliable differences in their response latencies for the use of spatial terms in the two different gravitational settings.

To test for a main effect of head position or an interaction involving this factor, an additional analysis was com- puted over the parts of the data from Experiments 1 and 2 that were comparable. Only the inflight $(L+1$ day) and the postflight ( $R+104 / 108$ day) data of the two experiments entered into the analysis, with the factors head position $x$ ball position $x$ tree orientation $x$ domain $x$ gravity. The analysis for PS2 revealed a main effect of gravity [inflight, $1,004 \mathrm{msec}$; postflight, $884 \mathrm{msec} ; F(1,1)$ $=252.46, p<.05$, accounting for $12.86 \%$ of the variance] and a tree orientation $\times$ domain $\times$ gravity interaction $[F(5,5)=8.15, p<.05$, accounting for less than $1 \%$ of the variance]. No other main effect or interaction was significant. For PS3, there was a significant main effect of head position [straight, $832 \mathrm{msec}$; tilt, 1,187 $\mathrm{msec}$; $F(1,1)=44,132.84, p<.01$, accounting for $23.80 \%$ of the variance]. The main effect of gravity failed to be significant (inflight, 1,144 msec; postflight, $874 \mathrm{msec}$ ), due to a large variation in the responses during the headtilt inflight test (see Table 4). There were two interactions involving the factor of gravity, but neither was significant at the $1 \%$ level of significance: domain $\times$ gravity $[F(1,1)$ $=250.97, p<.05]$ and ball $\times$ domain $\times$ gravity $[F(2,2)$ $=44.88, p<.05$ ], each accounting for less than $1 \%$ of the variance. No other interaction reached the $5 \%$ level of significance.

The factor of head position turns out to be significant for PS3, with faster reaction times under the head straight than under the head-tilt condition, but not for PS2. Interestingly, for both subjects, this factor does not interact with any other factor in a significant way. If these results are valid, the data of PS2 would have to be taken as evidence for a mechanism of spatial assignment that is, in principal, flexible enough to use different reference frames as the perceptual cues change. The data of PS3, however, may be taken to suggest that the system's efficiency to do so depends on the particular cues available and on how they are perceived.

In sum, then, the finding of Experiments 1 and 2, that adequate and consistent spatial assignment is possible immediately after first exposure to microgravity with only some increase in computational load, leads to the assumption that the cognitive representations of space used under these perceptual circumstances are not entirely reconstructed on the basis of new perceptual information. The cognitive system relies rather on an already established representational framework, onto which new input information can be mapped. The finding that the difference in performance between the preflight and the inflight tests is relatively small is all the more surprising, given that preflight testing occurred in a relatively relaxed situation, whereas inflight tests were conducted in a situation in which some physiological parameters appear to be changed (Baumgarten et al., 1987) and in which mental stress due to the general strict timeline of space missions cannot be excluded. The quick adaptation of spatial assignment under weightlessness observed in these experiments occurred despite physiological changes in optokinetic and vestibulo-ocular reflexes (Baumgarten et al., 1987; Mittelstaedt, 1987). This may be taken as evidence 

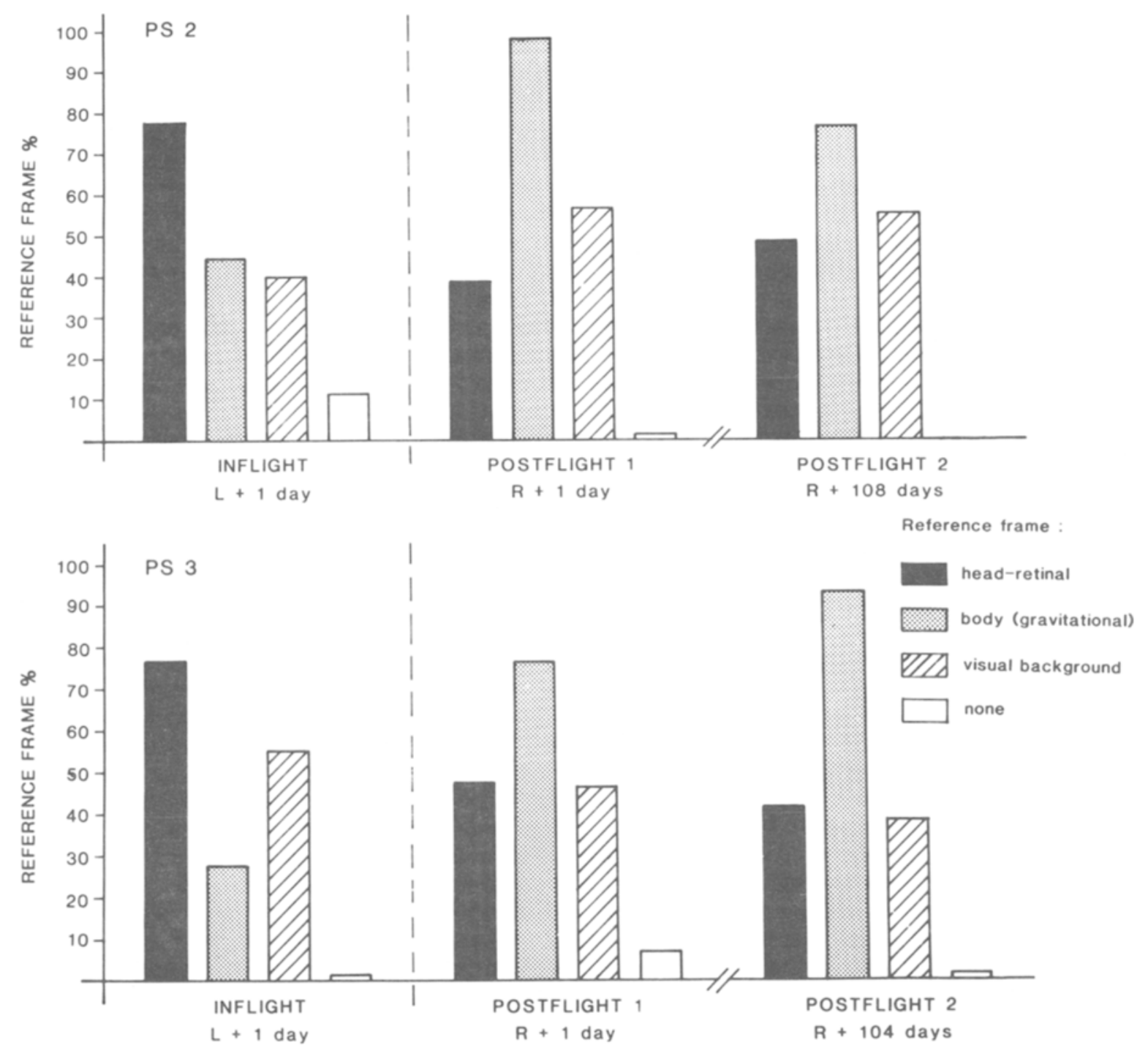

Figure 6. Percentages of reference choice for PS2 and PS3 under head-tilt condition.

that the observed adaptation goes beyond the physiological parameters measured so far. ${ }^{1}$ A similar claim that adaptive processes may be influenced by mental factors has recently been put forward by Melvill-Jones and Berthoz (1985), who raise the possibility that internal, neurally encoded reference signals may be changed by the application of mental effort alone.

Although the data base of the present experiments is limited, the results suggest that observed adaptation may be characterized in procedural terms. In weightlessness, where a perceptual cue such as gravity is nearly absent, and where body awareness may be less salient, subjects use the retinal reference frame to guide their use of spatial terms. Mappings from a novel perceptual input to the mental representation of space seem to be available immediately. As exposure to the perceptually novel situation increases, these apparently become more and more automatic.

The direct comparison of Experiments 1 and 2 indicates that the head position may affect the subject's spatial assignment when gravity is present, but not when it is absent. This suggests a differential involvement of the various reference systems in spatial assignment as the perceptual situations differ. Spatial assignment may possibly be achieved simply by putting dominant weight on one of the various perceptual cues. These results can be discussed in connection with findings from perceptual tasks. In a luminous line setting task under a body posi- 
Table 4

Experiment 2: Mean Reaction Times in Milliseconds per Subject and Condition

\begin{tabular}{|c|c|c|c|c|}
\hline \multirow[b]{2}{*}{ Subject } & \multicolumn{2}{|c|}{$\begin{array}{c}\text { Inflight } \\
\mathrm{L}+1 \text { day }\end{array}$} & \multicolumn{2}{|c|}{$\begin{array}{c}\text { Postflight } \\
R+108 \text { days/ } \\
R+104 \text { days }\end{array}$} \\
\hline & $M$ & $S D$ & $M$ & $S D$ \\
\hline $\begin{array}{l}\text { PS2 } \\
\text { PS3 }\end{array}$ & $\begin{array}{r}963 \\
1508\end{array}$ & $\begin{array}{l}114 \\
348\end{array}$ & $\begin{array}{l}910 \\
865\end{array}$ & $\begin{array}{l}199 \\
164\end{array}$ \\
\hline
\end{tabular}

tion in which gravitational cues cannot be used as a frame of reference-that is, when subjects are in a supine position (Parker et al., 1983) - a behavioral difference with the upright body position was found when the head was straight, but not when the head was tilted. Relating these results to those in the previous experiments, it seems not implausible that subjects in a supine position with gravitational cues present but task-irrelevant might react similarly to subjects in a situation in which gravitational cues are absent altogether. If so, the horizontal supine body position might be considered as a possible condition under which future astronauts could be trained for their stays in weightlessness-at least with respect to spatial cognitive aspects.

In order to test this hypothesis, we conducted a third experiment, with a larger group of subjects who had to perform the same task as the astronauts but under $1 \mathrm{~g}$ in a horizontal supine position.

\section{EXPERIMENT 3}

The primary goal of Experiment 3 was to establish what kind of reference frame subjects use for spatial assignment in the absence of task-relevant gravitational cuesthat is, when in a horizontal supine position.

\section{Method}

\section{Subjects}

There were 14 subjects, all with normal or corrected-to-normal vision. All subjects were native speakers of Dutch drawn from a student subject pool. They were paid for their participation.

\section{Stimuli}

The stimuli were the same as in Experiments 1 and 2 .

\section{Procedure}

The subjects were tested individually. Each subject had to perform three experimental runs all in a horizontal supine position (lying on their backs): one with the head straight, one with the head tilted to the left, and one with the head tilted to the right. The inclination of the head's tilt was $35^{\circ}$ off the body's vertical. The task was the same as in Experiments 1 and 2. No instruction for reference choice was given. During the task, the subject lay with the back on a horizontally positioned board. The subject's axes of body and head were oriented with marks on a padded cloth indicating head straight or tilted by $35^{\circ}$ toward the left or right shoulder. An oval half ring of foam rubber was used to fix the subject's head. All subjects performed the task with 72 items under the head straight condition first; then, half of the subjects performed the same task by tilting the head first to the right ( 72 items) and next to the left side ( 72 items), whereas the other half of the subjects performed the head tilt condition in reversed order. The stimuli were presented in the VISOS apparatus described in Experiment 1. The apparatus was mounted on a tripod that allowed movements of the VISOS' plane in all directions.

The plane in which the stimulus material was presented was adjusted individually for each subject. In order to avoid influences from interindividual differences due to the individual's subjective zenith (Mittelstaedt, 1983), the plane was not installed parallel to the floor but was individually adjusted to the individual's subjective zenith. This was achieved by displaying a white point on a black background in the middle of the display, and by asking the subject to manually move the VISOS back and forth until he felt that the white point was exactly at the zenith. The investigator noted the subject's deviance from the objective vertical indicated by a perpendicular. This procedure was repeated three times, following which the VISOS was fixed in a position based on the mean of the three measures.

\section{Results}

Verbal responses were analyzed as in Experiments 1 and 2.

\section{Reference Choice}

The mean percentage of reference choice under the head straight condition demonstrates a clear preference for the coordinates jointly indicated by the body-defined and the head-retinal vertical $(61.9 \%)$ over the vertical indicated by the visual background $(22.7 \%)[\mathrm{t}(13)=6.75$, $p<.001$; ;ee Table 5. All verbal responses correct with respect to the visual background $(X$-inclusive $=22.7 \%)$ are to a large extent at the same time correct with respect to the frame indicated by the body-defined and head-retinal axes. The number of responses correct exclusively with respect to the visual background is low ( $X$-exclusive $=$ $10.35 \%)$.

Table 5

Experiment 3: Percentages of Responses with Respect to Different Reference Frames per Subject (Head Straight)

\begin{tabular}{lccc} 
& \multicolumn{3}{c}{ Reference Frame } \\
\cline { 2 - 4 } Subject & None & $\begin{array}{c}\text { Head- } \\
\text { Retinal }\end{array}$ & $\begin{array}{c}\text { Visual } \\
\text { Background }\end{array}$ \\
\hline SU1 & 15.3 & 23.6 & 88.3 \\
SU2 & 16.7 & 80.1 & 16.7 \\
SU3 & 12.5 & 79.2 & 21.7 \\
SU4 & 16.7 & 79.2 & 18.3 \\
SU5 & 19.4 & 73.6 & 20.0 \\
SU6 & 34.7 & 59.7 & 16.7 \\
SU7 & 29.2 & 69.4 & 15.0 \\
SU8 & 50.0 & 44.4 & 11.7 \\
SU9 & 36.1 & 55.6 & 21.7 \\
SU10 & 30.6 & 65.3 & 16.7 \\
SU11 & 38.9 & 52.8 & 21.7 \\
SU12 & 22.2 & 70.8 & 23.3 \\
SU13 & 34.7 & 62.5 & 15.0 \\
SU14 & 47.2 & 50.0 & 11.7 \\
$M$ & 28.9 & 61.9 & 22.7 \\
\hline
\end{tabular}


Table 6

Experiment 3: Percentage of Responses with Respect to Different Reference Frames per Subject (Head Tilt)

\begin{tabular}{lrccc} 
& \multicolumn{4}{c}{ Reference Frame } \\
\cline { 2 - 5 } Subjects & None & $\begin{array}{c}\text { Head- } \\
\text { Retinal }\end{array}$ & Body & $\begin{array}{c}\text { Visual } \\
\text { Background }\end{array}$ \\
\hline SU1 & 16.0 & 18.8 & 8.3 & 91.7 \\
SU2 & 20.8 & 60.4 & 34.0 & 11.7 \\
SU3 & 10.4 & 61.8 & 56.9 & 20.8 \\
SU4 & 9.0 & 72.9 & 47.9 & 18.3 \\
SU5 & 11.1 & 79.2 & 39.6 & 16.7 \\
SU6 & 17.4 & 71.5 & 34.7 & 19.2 \\
SU7 & 11.8 & 66.0 & 53.5 & 15.3 \\
SU8 & 32.6 & 56.9 & 23.6 & 16.7 \\
SU9 & 36.8 & 48.6 & 21.5 & 19.2 \\
SU10 & 20.1 & 70.8 & 31.3 & 18.3 \\
SU11 & 34.7 & 55.6 & 17.4 & 20.0 \\
SU12 & 16.0 & 64.6 & 44.4 & 21.7 \\
SU13 & 16.7 & 80.6 & 25.7 & 13.3 \\
SU14 & 27.8 & 61.1 & 34.7 & 11.1 \\
$M$ & 20.1 & 62.0 & 33.8 & 22.4 \\
\hline
\end{tabular}

There was a significant preference for the head-retinal (62.0\%) over the body-defined (33.8\%) reference frame $[t(13)=7.91, p<.001]$ under head tilt calculated over the $X$-inclusive data.

Inspection of the individual subject data (see Table 6) under head tilt revealed that for 1 out of 14 subjects (SU1) the visual background acted as the dominant frame. For 13 out of 14 , there was a clear preference for the headretinal coordinates as the dominant reference frame. The 13 subjects only differed in the relative weights they gave to the dominant frame and in how successful their weighting procedures were. It should be noted that, in general, the subjects' reference choices were independent of their indicated subjective zeniths as measured in this experiment. There was no significant correlation between the subjective zenith scores and the mean percentages of headretinal reference choices $(r=-0.072)$ or body-defined reference choices $(r=0.016)$. Figure 7 displays the mean percentages of reference choice for these 13 subjects.

\section{Response Latency}

The reaction time data presented are the latencies measured as in Experiments 1 and 2. Extreme values, defined as response latencies that were off the condition's mean by two standard deviations or more, and missing data points (a total of $4.8 \%$ ) were replaced by the condition's mean. A first ANOVA was calculated over the head tilt conditions with only the factors head position (left/right) $x$ domain (horizontal/vertical) $\times$ ball positioin $\times$ tree orientation. Because there was neither a significant main effect of head position $(F<1)$ nor a significant interaction involving this factor, data from the head left and head right conditions were pooled together for further analysis. Individual means were calculated over the data points (head left / head right) for each stimulus item, providing 72 data points (head tilt) that were entered into an ANOVA comparing head straight versus head tilt response laten- cies. The response latencies of the different conditions are displayed in Table 7.

An ANOVA with four factors-head position (straight, tilt) $\times$ domain (horizontal, vertical) $\times$ ball position (rectilinear, oblique $-7^{\circ}$, oblique $+7^{\circ}$ ) $\times$ tree orientation (rectilinear, oblique $-14^{\circ}$, oblique $-7^{\circ}$, oblique $+7^{\circ}$, oblique $+14^{\circ}$, no tree)-was calculated over subjects. All main effects were significant, head position $[F(1,13)=$ $7.56, p<.05]$ with longer reaction times for the head straight than for the head tilt condition. The main effect of domain $[F(1,13)=4.5, p<.05]$ was due to longer reaction times for the vertical than for the horizontal domain. The main effect of ball position $[F(2,26)=5.30$, $p<.05$ ] reflects overall longer reaction times to those visual displays in which the ball position was nonoblique $\left(90^{\circ}, 180^{\circ}, 270^{\circ}\right.$, and $\left.360^{\circ}\right)$ than to those in which the ball position was oblique $\left( \pm 7^{\circ}\right)$. The main effect of tree orientation $[F(5,65)=2.61, p<.05]$ was also significant, with faster reaction times for displays with trees in nonoblique than in oblique positions. There was a significant domain $\times$ tree orientation interaction $[F(5,65)=9.1, p<$ $.001]$ as well as a ball position $\times$ tree orientation interaction $[F(10,130)=6.24, p<.001]$ and a domain $\times$ ball position $\times$ tree orientation interaction $[F(10,130)=$ $2.82, p<.01]$. No other interaction was significant.

\section{Discussion}

It is clear from Experiment 3 that when subjects are asked to verbally describe visual arrays in a situation where gravitational cues cannot serve as a reference frame, they tend to take the head-retinal coordinates as a primary reference-at least with a visual background like the one tested here. This result can be related to findings from spatial orientation experiments, in which

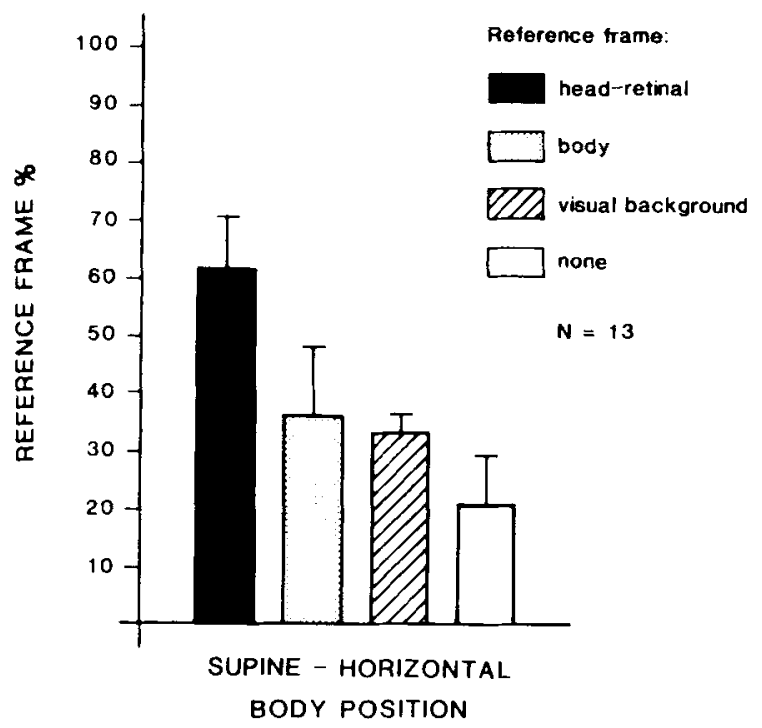

Figure 7. Mean percentages of reference choice for 13 subjects in horizontal supine body position. 
Table 7

Experiment 3: Mean Reaction Times in Milliseconds for 14 Subjects (Horizontal Supine Position)

\begin{tabular}{lcc}
\hline & \multicolumn{2}{c}{ Condition } \\
\cline { 2 - 3 } Ball Position & Head Straight & Head Tilt \\
\hline Overall mean & 1,273 & 1,140 \\
Horizontal & 1,251 & 1,111 \\
Ball $-7^{\circ}$ & 1,257 & 1,137 \\
Ball 0 & 1,280 & 1,105 \\
Ball $+7^{\circ}$ & 1,217 & 1,090 \\
Vertical & 1,294 & 1,168 \\
Ball $-7^{\circ}$ & 1,292 & 1,153 \\
Ball 0 & 1,320 & 1,239 \\
Ball $+7^{\circ}$ & 1,270 & 1,111 \\
\hline
\end{tabular}

primacy of head-retinal cues has been observed during a line setting task in supine position (Rock, 1956).

The reaction time results indicate that the perceptual factors introduced in Experiment 3 all affect verbal spatial assignment. Furthermore, the two-way and three-way interactions indicate that some but not all factors interact during spatial assignment. Most interestingly, head position does not interact with any of the other perceptual factors. Subjects' reaction times are in general longer when the head is straight than when the head is tilted. This suggests that, in a supine position, subjects do not gain facilitation from the fact that the head-retinal and the bodydefined axes are aligned. On the contrary, it seems that this leads to a higher computational load when spatial assignment is required. The observed ball position $\times$ tree orientation interaction shows that the visual background of the trees, although rarely chosen as the primary reference, affects the process of spatial assignment in a systematic way. When the ball position is rectilinear, reaction times are dramatically slowed down, in particular when tree orientation deviates by $7^{\circ}$ off rectilinear, but not when it deviates by $14^{\circ}$ off-rectilinear (tree orientation: $-7^{\circ}, 1,595 \mathrm{msec} ;+7^{\circ}, 1,558 \mathrm{msec} ;-14^{\circ}$, $\left.1,344 \mathrm{msec} ;+14^{\circ}, 1,388 \mathrm{msec}\right)$, as compared with the situation in which the tree orientation is rectilinear $(1,376 \mathrm{msec})$.

The reaction time data from Experiment 3 support in general the view of a weighting procedure that takes place when spatial positions have to be assigned. During this procedure, different perceptual cues, the head-retinal orientation of the visual cue itself (here, ball position), and the visual background (here, tree orientation) are weighted during spatial assignment. Although subjects, as was shown in the choice of reference analysis, use the head-retinal coordinates as their primary reference frame, the visual background interferes with the target head-retinal information, in particular when the orientation of the visual background and target differ by only some degrees. It is interesting that subjects' overall reaction times are longer in the supine position when their heads are straight than when their heads are tilted. The additional information that is provided by the alignment of the head-retinal vertical and the body-defined vertical does not seem to facilitate weighting procedures in the supine positionthat is, in a perceptual situation in which the body-defined vertical does not coincide with the gravitational vertical. This suggests that the weighting observed here cannot be modeled as a simple additive procedure when more than one cue indicates the same vertical.

\section{GENERAL DISCUSSION}

The results from the 2 subjects tested under the exceptional perceptual condition of weightlessness demonstrate that spatial concepts can be used unambiguously in the absence of the perceptual cues normally provided by gravity. They substantiate that, in weightlessness, subjects predominantly use the head-retinal vertical as a reference frame, whereas on earth, the gravitationally defined vertical is used when possible. The gravitational coordinate system is most dominantly used as a reference frame when it coincides with the body-defined vertical. The latter finding is consistent with a number of earlier studies on spatial perception and orientation under $1 \mathrm{~g}$ conditions, in which subjects in an upright sitting or standing position were tested with their heads tilted. These studies had shown that although subjects sometimes used a reference frame that lay between the gravitational and the retinal coordinates, gravitational coordinates were dominant for the adult subjects' reference choices during perception of space or orientation in space (Attneave \& Olson, 1967; Corballis, Nagoury, et al., 1978). The present data add to the previous findings by demonstrating a dominance of the gravitational frame as the reference when using spatial terms. The results from the additional experiment conducted with a group of subjects under a condition where gravitational cues were present but task-irrelevant show that subjects are able to switch to a reference frame other than the one normally used when one is standing upright. The finding that the reference frame used in the horizontal supine position is the same as that used under microgravity-namely, the head-retinal reference frame-might be considered as a basis for future training programs for astronauts.

As for the nature of the mental representations underlying spatial assignment, the present study clearly shows that although on earth gravity plays a dominant role for the choice of spatial reference in adults, mental representations or concepts of spatial orientation can be used quite consistently in its absence. The choice of the reference frame with respect to which spatial terms are used, however, is not uninfluenced by the different perceptual cues given. When gravitational cues are absent or taskirrelevant, subjects tend to use the head-retinal reference system. The data thus indicate that perceived gravity is not a necessary condition for consistent spatial assignment. This suggests that the mental representation of space may encode verticality in a form that is independent of a particular percept. Such a representational form would guarantee immediate mappings of novel perceptual information onto it. 
Another mechanism that would guarantee immediate mappings from various perceptual situations onto a mental representation would require space to be multiply coded with respect to different perceptual aspects. So far, distinct spatial maps have been demonstrated for the motor and the cognitive domains (Bridgeman, Lewis, Heit, \& Nagle, 1979). Whether distinct spatial maps are to be assumed for different perceptual domains, however, is currently unclear.

In conclusion, the present data show that spatial assignment is possible in dramatically novel perceptual situations, such as weightlessness, and they suggest that this is achieved on the basis of a mental representation of space that is independent of the particular percept of gravity.

\section{REFERENCES}

Attneave, F., \& Olson, R. K. (1967). Discriminability of stimuli varying in physical and retinal orientation. Journal of Experimental Psychology, 74, 149-157.

AUBERT, H. (1861). Über eine scheinbare Drehung von Objekten bei Neigung des Kopfes nach rechts oder links. Virchows Archiv, 20, 381-393.

Baumgarten, R. von, Benson, A., Berthoz, A., Bles, W., Brandt, T., Brenske, A., Clark, A., Dichgans, J., Eggertsberger, R., Jürgens, K., Kass, J., Krafczky, S., Probst, T., SCherer, H., Thümler, R., VieVille, T., Vogel, H., \& WeTzig, J. (1987). European experiments on the vestibular system during the Spacelab D-1 Mission. In P. R. Sahm, R. Jansen, \& M. H. Keller (Eds.), Scientific results of the German Spacelab Mission D-1 (pp. 518524). Köln: Deutsche Forschungs- und Versuchsanstait für Luft- und Raumfahrt.

Bischof, N., \& Scheerer, E. (1970). Systemanalyse der optischvestibulären Interaktion bei der Wahrnehmung der Vertikalen. Psychologische Forschung, 34, 99-181.

Bridgeman, B., Lewis, S., Heit, G., Nagle, M. (1979). Relation between cognitive and motor-oriented systems of visual position perception. Journal of Experimental Psychology: Human Perception \& Performance, 5, 692-700.

Corballis, M. C., Anuza, T., \& Blake, L. (1978). Tachistoscopic perception under head tilt. Perception \& Psychophysics, 24, 274-284.

Corballis, M. C., Nagoury, B. A., Shetzer, L. I., \& Stefanatos, G. (1978). Mental rotation under head tilt: Factors influencing the location of the subjective reference frame. Perception \& Psychophysics, 24, 263-273.

Dichgans, J., Held, R., Young, L., \& Brandt, T. (1972). Moving visual scenes influence the apparent direction of gravity. Science, 178 , 1217-1219.

Ebenholtz, S. M. (1977). Determinants of the rod and frame effect: The role of retinal size. Perception \& Psychophysics, 22, 531-538.

FRIEDERICI, A. D. (1989a). Raumreferenz unter extremen perzeptuellen Bedingungen: Perzeption, Repräsentation und sprachliche Abbildung. In C. Habel, M. Herweg, \& K. Rehkämper (Eds.), Raumkonzepte in Verstehensprozessen (pp. 17-36). Tübingen: Niemeyer.

FRIEDERICI, A. D. (1989b, September/October). Spatial assignment in extreme perceptual conditions: Mechanisms of human adaptation. Paper presented at the 8th International Academy of Astronautics' Man in Space Symposium, Tashkent, USSR.

Friederici, A. D., Levelt, W. J. M. (1986). Cognitive processes of spatial coordinate assignment: On weighting perceptual cues. Natur wissenschaften, $73,455-458$.

Friederici, A. D., Le Lelt, W. J. M. (1987, September). Resolving perceptual conflicts: The cognitive mechanism of spatial orientation. Aviation, Space, \& Environmental Medicine, pp. A164-A169.

Graybiel, A., Miller, E. F. II, Billungham, J., Waite, R., Berry, C. A., \& DietLeIN, L. F. (1967). Vestibular experiments in Gemini flights V and VII. Aerospace Medicine, 38, 360-370.
Kohler, J. (1955). Die Methode des Brillenversuchs in der Wahrnehmungspsychologie mit Bemerkungen zur Lehre von der Adaption. Zeitschrift für Experimentelle Angewandte Psychologie, 3, 381-417.

Kosslyn, S. M., ShwarTz, S. P. (1978). Visual images as spatial representations in active memory. In E. M. Riseman \& A. R. Hanson (Eds.), Computer vision. New York: Academic Press.

LEVELT, W. J. M. (1984). Some perceptual limitations in talking about space. In A. J. Van der Grind \& J. J. Koenderink (Eds.), Limits in perception (pp. 323-358). Utrecht: VNU Science Press.

Mauritz, K. H., Dichgans, J., \& Hufschmidt, A. (1977). The angle of visual roll motion determines displacement of subjective visual vertical. Perception \& Psychophysics, 22, 557-562.

Melvill-Jones, G., \& BerTHOZ, A. (1985). Mental control of the adaptive process. In A. Berthoz \& G. Melvill-Jones (Eds.), Adaptive mechanisms in gaze control: Facts and theories (pp. 203-208). Amsterdam: Elsevier

MitTElstaedT, H. (1983). A new solution to the problem of subjective vertical. Naturwissenschafien, 70, 272-281.

MitTeLstaEDT, H. (1987). Inflight and postflight results on the causation of inversion illusions and space sickness. In P. R. Sahm, R. Jansen, \& M. H. Keller (Eds.), Scientific results of the German Spacelab Mission D-I (pp. 525-536). Köln: Deutsche Forschungs- und Versuchsanstalt für Luft- und Raumfahrt.

MüLleR, G. E. (1916). Über das Aubertsche Phänomenon. Zeitschrift für Psychologie und Physiologie der Sinnesorgane, 49, 109-246.

Parker, D. E., Poston, R. L., \& Gulledge, W. L. (1983). Spatial orientation: Visual-vestibular-somatic interaction. Perception \& Psychophysics, 33, 139-146.

Pinker, S. (1980). Mental imagery and the third dimension. Journal of Experimental Psychology: General, 109, 354-371.

Pinker, S., \&osslyn, S. M. (1978). The representation and manipulation of three-dimensional space in mental images. Journal of Mental Imagery, 2, 69-84.

Pylyshyn, Z. W. (1973). What the mind's eye tells the mind's brain: A critique of mental imagery. Psychological Bulletin, 80, 1-24.

Pylyshyn, Z. W. (1980). Computation and cognition: Issues in the foundations of cognitive science. Behavioral \& Brain Sciences, 3, 111-132.

Rock, I. (1956). The orientation of forms on the retina and in the environment. American Journal of Psychology, 69, 513-528.

Rock, I. (1973). Orientation and form. New York: Academic Press.

SHEPARD, R. N., \& HURWITZ, S. (1984). Upward direction, mental rotation, and discrimination of left and right turns in maps. Cognition, 18, 161-194.

Templeton, W. B. (1973). The role of gravitational cues in the judgment of visual orientation. Perception \& Psychophysics, 14, 451-457. voN Holst, E. (1950). Die Arbeitsweise des Statolithenapparates bei Fischen. Zeitschrift für Vergleichende Physiologie, 32, 60-120.

WITKIN, H. A., \& AsCH, S. L. (1948). Studies in space orientation: IV. Further experiments on perception of the upright with displayed visual fields. Journal of Experimental Psychology, 38, 762-782.

Young, L. R., Oman, C. M., KenYon, R. V., ARRotT, A. P. (1986). Sensory adaptation to weightlessness and readaptation to one-g: An overview. Experimental Brain Research, 64, 291-298.

Young, L. R., Oman, C. M., Watt, D. G. D., Money, K. E., \& LiChTENBERG, B. K. (1984). Spatial orientation in weightlessness and readaption to earth's gravity. Science, 225, 205-208.

\section{NOTE}

With respect to a possible interference of space sickness with the present experiment, we may refer to Mittelsteadt (1987), who reports that PS3 (Astronaut I) had no vomiting episode during the entire space mission, and that PS2 (Astronaut G) had his last spontaneous vomiting episode at mission elapsed time of 0.3 days. Both astronauts reported that they conducted the present experiment without major physiological problems.

(Manuscript received March 17, 1989; revision accepted for publication September 27, 1989.) 